\title{
Analisis Aspek Permodalan Koperasi Karyawan Bank Mandiri Wilayah II Palembang
}

\author{
Dwi Melinda Putri ${ }^{1}$, Yasir Arafat ${ }^{1}$, Riswan Aradea $^{1}$ \\ ${ }^{1}$ Universitas PGRI Palembang
}

$\triangle$ Corresponding author

(dwi.melinda28@gmail.com)

\begin{abstract}
Abstrak
Penelitian ini bertujuan untuk mengetahui dan menganalisis aspek permodalan pada Koperasi Karyawan Bank Mandiri Wilayah II Palembang tahun 2017 - 2019 berdasarkan Peraturan Deputi Bidang Pengawasan Kementerian Koperasi Dan Usaha Kecil Menengah Republik Indonesia No : 06/Per/Dep.6/IV/2016. Data yang digunakan dalam penelitian ini berupa data primer dan sekunder. Data primer diperoleh dari laporan keuangan koperasi karyawan Bank Mandiri Wilayah II Palembang. Sedangkan data sekunder diperoleh dari observasi dan dokumentasi. Teknik analisis data menggunakan teknik deskriptif kualitatif di mana data yang diperlukan, dianalisis lalu kemudian hasil analisis tersebut dideskripsikan dalam bentuk kata. Hasil penelitian dan pembahasan yang telah dilakukan terhadap aspek permodalan pada Koperasi Karyawan Bank Mandiri Wilayah II palembang tahun 2017 sampai 2019 berada dalam kategori sehat.
\end{abstract}

Kata kunci. Laporan Keuangan; Aspek Permodalan; Sehat

\begin{abstract}
This study aims to determine and analyze the capital aspect of the Bank Mandiri Regional II Palembang Employee Cooperative in 2017 - 2019 based on the Regulation of the Deputy for Supervision of the Ministry of Cooperatives and Small and Medium Enterprises of the Republic of Indonesia No: 06/Per/Dep.6/IV/2016. The data used in this study are primary and secondary data. Primary data was obtained from the financial statements of the employee cooperatives of Bank Mandiri Region II Palembang. While secondary data obtained from observation and documentation. The data analysis technique uses a qualitative descriptive technique where the required data will be analyzed and then the results of the analysis are described in written form. The results of research and discussion that have been carried out on the capital aspect of the Bank Mandiri Regional II Employee Cooperative in Palembang from 2017 to 2019 are in the healthy category.
\end{abstract}

Keywords. Financial Statements, Capital Aspect, Healthy

\section{PENDAHULUAN}

Pembangunan ekonomi pada saat ini di Indonesia sudah cukup baik dan berkembang dapat dilihat di era pemerintahan yang memimpin negara ini yaitu orde lama, orde baru dan orde reformasi.. Pada era pemerintahan orde lama telah diselenggarakan kongres koperasi beberapa kali sehingga peraturan tentang koperasi disahkan. Sedangkan pada masa orde baru pemerintah mengeluarkan undang-undang perkoperasian yang berisi tentang pokok-pokok perkoperasian. Undang-undang tersebut adalah UU No. 12 tahun 1967 yang salah satu isinya tentang kedudukan hukum koperasi sebagai organisasi ekonomi rakyat yang berwatak sosial yang di dalamnya beranggotakan oleh badan-badan hukum koperasi yang berasas pada kekeluargaan. Kemudian di masa era reformasi koperasi sangat penting karena mempunyai peranan yang mendukung perkembangan pada zaman ini semakin meningkat dalam pengelolaan koperasi. Dalam hal ini koperasi mempunyai peranan yang sangat penting dalam penataan lembaga keuangan koperasi di dalam gerakan koperasi yang otonom mampu membantu aktivitas ekonomi masyarakat yang 
berada di lapisan terbawah seperti usaha mikro dapat terbantu dalam segi modal pembiayaan agar usaha tersebut dapat berjalan lancar (Subandi, 2015).

Dari pengertian di atas maka dapat dikatakan bahwa koperasi mempunyai arti badan hukum koperasi yang melandaskan pada asas kekeluargaan bersama untuk memperbaiki dan membantu perekonomian dengan tolong menolong dalam pertumbuhan di Indonesia. Untuk melakukan penilaian koperasi data yang dapat di gunakan yaitu laporan keuangan tahunan satu periode atau satu tahun pada saat pembukuan akhir tahun. Sesuai dengan bentuk nya koperasi sebagai bangun usaha maka koperasi memiliki tujuan mencapai keuntungan laba atau Sisa Hasil Usaha.

Oleh sebab itu dalam melakukan penilaian koperasi pemerintah mengeluarkan Peraturan Pengawasan Kementerian Koperasi dan Usaha Kecil Menengah (UKM) Republik Indonesia No: 06/Per/Dep/IV/2016 tentang mengenai Pedoman Penilaian Kesehatan Simpan Pinjam dan Unit Simpan Pinjam Koperasi. dengan menganalisis laporan keuangan tersebut menggunakan standar penilaian yang terdiri dari Aspek Permodalan yang terdapat pada Peraturan Pengawasan Kementerian Koperasi Dan Usaha Kecil Menengah (UKM) Republik Indonesia No: 06/Per/Dep/IV/2016 tentang pedoman penilaian kesehatan koperasi simpan pinjam dan unit simpan pinjam koperasi (Kurniawan dan Arianti, 2018).

Koperasi Karyawan Bank Mandiri Wilayah II Palembang merupakan unit koperasi yang bergerak dibidang simpan pinjam, warung serba ada, cleaning service, penyediaan tenaga kerja dan usaha lainnya. Dalam melakukan kegiatannya usaha yang dilakukan berupa pemberian secara kredit kepada anggota koperasi. Koperasi Karyawan Bank Mandiri bertugas memberikan pelayanan seperti pinjaman dan memberikan kebutuhan para anggotanya, sumber dana koperasi karyawan bank mandiri diperoleh dari simpanan pokok, simpanan wajib dari anggota sesuai ketentuan dan lembaga lainnya yang mengalami kelebihan dana.

Pada koperasi ini diketahui terdapat beberapa anggota yang meminjam uang kemudian terlambat membayar uang pinjaman koperasi sedangkan uang simpanan dan tagihan dari anggota koperasi tidak sebanding dengan jumlah yang dipinjam. Maka hal ini menjadi masalah bagi Koperasi Karyawan Bank Mandiri karena akan menyebabkan kekurangan modal dan dana karena akan menghambat bagi anggota lain yang ingin meminjam uang oleh karena itu akan dikhawatirkan mengalami penurunan dalam perhitungan dan pembagian Sisa Hasil Usaha. Pada umumnya koperasi merupakan badan usaha yang memerlukan alat untuk menilai kinerja keuangan biasanya digunakan rasio sebagai tolak ukur guna membandingkan beberapa laporan keuangan dari periodeperiode yang telah terjadi, dengan menggunakan analisis laporan keuangan tersebut dapat diketahui tingkat perbandingan berbagai rasio yang dapat diolah guna kepentingan dan kemajuan pada badan usaha. Berikut ini Neraca Koperasi Karyawan Bank Mandiri Wilayah II Palembang periode 2017-2019.

\section{Tabel 1. Neraca Koperasi Karyawan Bank Mandiri Wilayah II Palembang Periode 2017-2019 (Dalam Rupiah)}

\begin{tabular}{cccc}
\hline \multirow{2}{*}{ Tahun } & Total Aset & $\begin{array}{c}\text { Akun } \\
\text { Total Liabilitas }\end{array}$ & Total Ekuitas \\
\hline 2017 & $2.964 .720 .659,15$ & $1.029 .841 .158,14$ & $1.934 .878 .901,02$ \\
2018 & $2.243 .318 .350,00$ & $631.573 .246,13$ & $1.611 .745 .103,87$ \\
2019 & $1.155 .465 .507,42$ & $306.389 .228,89$ & $300.227 .741,53$ \\
\hline \multicolumn{4}{c}{ Sumber: Koperasi Karyawan Bank Mandiri Wilayah II Palembang }
\end{tabular}

Dari tabel di atas dapat dilihat bahwa struktur aset secara keseluruhan mengalami penurunan dimana dibuktikan pada tahun 2018 menuju ke 2019 total aset mengalami penurunan sebesar Rp 1.087.852.843 yang membuat total aset pada tahun 2019 memiliki penurunan rendah jika dibandingkan dengan tahun sebelumnya. Walaupun pada tahun 2019 total aset mengalami penurunan namun total aset pada tahun ini secara keseluruhan total aset yang dimiliki oleh koperasi ini masih dapat dikelompokkan dalam kategori yang cukup baik, hal ini dikarenakan total aset yang dimiliki koperasi selama 3 tahun terakhir masih lebih besar dari pada total liabilitasnya. 
Kemudian untuk struktur modal atau ekuitas koperasi karyawan bank mandiri wilayah II Palembang secara keseluruhan selama tahun 2017-2019 berada dalam kategori cukup baik karena ekuitasnya masih lebih besar dari pada total liabilitasnya.dan jika dilihat pada tahun 2017-2018 antara total aset, total liabilitas dan total ekuitas koperasi ini mengalami penurunan maka dalam kinerja aspek permodalan koperasi belum dapat dilakukan (Baswir, 2013). Dalam pengukuran kinerja permodalan sendiri sangatlah berguna bagi badan usaha untuk menilai pertumbuhan modal koperasi dan berguna untuk membandingkan badan usaha lainnya yang sejenis sehingga apabila suatu saat nanti terjadi kekeliruan maka hasil dari pengukuran kinerja tersebut dapat dijadikan bahan pertimbangan dalam sebuah keputusan tindakan apa yang akan dilakukan dalam memperbaiki kekeliruan tersebut. Berdasarkan uraian tersebut peneliti tertarik melakukan analisis laporan penilaian keuangan koperasi sehingga dalam penyusunan skripsi yang berjudul "Analisis Aspek Permodalan Koperasi Karyawan Bank Mandiri Wilayah II Palembang".

Hasil penelitian yang dilakukan oleh Sudiyanto (2019) mendapatakan hasil bahwa Koperasi Multi Kharisma Banyuasin Tahun 2014-2018 termasuk dalam kondisi sehat. Selanjutnya penelitian yang dilakukan oleh Sakdia (2019) yang mendapatkan hasil Analisis Penilaian Tingkat Kesehatan Aspek Permodalan Koperasi. Menemukan bahwa tingkat kesehatan permodalan koperasi berdasarkan rasio modal sendiri terhadap total asset dalam kategori buruk, rasio modal sendiri terhadap pinjaman diberikan yang beresiko kategori baik, dan rasio kecukupan modal sendiri pada kategori baik. Menurut Undang-undang No. 25 tahun 1992 pasal 1 koperasi adalah badan usaha yang beranggotakan orang-seseorang atau badan hukum koperasi dengan melandaskan kegiatannya berdasarkan prinsip koperasi sekaligus sebagai gerakan ekonomi rakyat yang berdasar atas asas kekeluargaan (Rudianto, 2010).

\section{METODE PENELITIAN}

Dalam penelitian ini yang digunakan yaitu metode kualitatif menggunakan laporan keuangan Koperasi Bank Mandiri Wilayah II Palembang. Menurut Sugiyono (2019) "metode deskriptif adalah menganalisis data dengan cara mendeskripsikan atau menggambarkan data yang telah terkumpul sebagaimana adanya tanpa bermaksud membat kesimpulan yang berlaku untuk umum atau generalisasi". Sumber data yang digunakan penulis pada penelitian ini adalah data primer dan data sekunder. Menurut Sugiyono (2019) "Sumber data primer merupakan sumber data yang langsung memberikan data kepada pengumpul data". Dari pendapat tersebut data yang digunakan peneliti yaitu data primer diperoleh dari laporan keuangan koperasi karyawan bank mandiri II Palembang periode tahun 2017 sampai tahun 2019. Sedangkan "Sumber data sekunder merupakan sumber yang tidak langsung memberikan data kepada pengumpulan data, misalnya lewat orang lain atau lewat dokumen", dari penjelasan tersebut maka data sekunder dapat diperoleh dari observasi dan dokumentasi (Moleong, 2017).

Dalam pengumpulan data yang digunakan penulis pada penelitian ini yaitu teknik Observasi dan dokumentasi. Menurut Arikunto (2013) "observasi merupakan suatu aktiva yang memperhatikan sesuatu dengan menggunakan mata". Teknik observasi ini digunakan untuk menggali informasi dan gambaran umum mengenai koperasi dan laporan keuangan koperasi karyawan bank mandiri II Palembang. Dokumentasi merupakan catatan peristiwa yang sudah berlalu, dokumentasi bisa berbentuk tulisan, gambar, atau karya-karya monumental dari seseorang" (Sugiyono, 2019) Dalam penelitian ini menggunakan teknik dokumentasi untuk memperoleh data laporan keuangan koperasi karyawan bank mandiri wilayah II Palembang seperti laporan neraca, laporan laba rugi, laporan sisa hasil usaha dan data pendukung lainnya. Teknik analisis data yang dilakukan dalam peneliti ini menggunakan analisis deskriptif yang digunakan untuk mengetahui gambaran keadaan data laporan keuangan Koperasi Karyawan Bank Mandiri Wilayah II Palembang yang berpedoman pada Peraturan Kementerian Koperasi dan Usaha Kecil Menengah No: 06/Per/Dep.06/IV/2016 dengan rincian rasio permodalan yaitu sebagai berikut.

a. Rasio modal sendiri terhadap total aset

$\frac{\text { Modal Sendiri }}{\text { Total aset }} \times 100 \%$

b. Rasio modal sendiri terhadap pinjaman yang berisiko

$\frac{\text { Modal sendiri }}{\text { Pinjaman diberikan yang beresiko }} \times 100 \%$ 
c. Rasio kecukupan modal sendiri

$\frac{\text { Modal Sendiri }}{A T M R} \times 100 \%$

\section{HASIL DAN PEMBAHASAN}

Dalam penilaian aspek permodalan koperasi terdapat 3 (tiga) rasio yaitu : rasio modal sendiri terhadap total aset, rasio modal sendiri terhadap pinjaman yang diberikan yang berisiko dan rasio kecukupan modal sendiri.

\section{Rasio Modal Sendiri Terhadap Total Aset}

Rasio modal sendiri terhadap total aset merupakan perbandingan antara modal sendiri dengan total aset yang dimiliki oleh Koperasi Karyawan Bank Mandiri Wilayah II Palembang pada tahun yang bersangkutan. Berikut ini hasil analisis rasio modal sendiri terhadap total aset pada koperasi karyawan bank mandiri wilayah II Palembang.

Rasio Modal Sendiri Terhadap Total Aset

$$
=\frac{\text { Modal Sendiri }}{\text { Total aset }} \times 100 \%
$$

Tahun $2017=\frac{\operatorname{Rp} 1.934 .878 .901,02}{\operatorname{Rp~} 2.964 .720 .059,1} \times 100 \%$

$$
=0.65263=65.26 \%
$$

$\begin{aligned} \text { Tahun } 2018= & \frac{\operatorname{Rp} 1.611 .745 .103,87}{\operatorname{Rp} 2.243 .318 .350,00} \times 100 \% \\ & =0.71846=71.84 \%\end{aligned}$

Tahun $2019=\frac{\operatorname{Rp} 849.076 .278,5}{\operatorname{Rp} 1.155 .465 .507} \times 100 \%$

$$
=0.73483=73.48 \%
$$

Berdasarkan perhitungan rasio modal sendiri terhadap total aset, selanjutnya dapat dilakukan penskoran pada hasil tersebut. Penskoran untuk rasio modal sendiri terhadap total aset disajikan dalam tabel berikut ini.

Table 2. Penskoran Rasio Modal Sendiri Terhadap Total Aset

\begin{tabular}{ccccc}
\hline Tahun & Rasio Modal (\%) & Nilai & Bobot (\%) & Skor \\
\hline 2017 & $65.26 \%$ & 50 & 6 & 3.00 \\
2018 & $71.84 \%$ & 50 & 6 & 3.00 \\
2019 & $73.48 \%$ & 50 & 6 & 3.00 \\
Rata-Rata & $70.19 \%$ & 50 & 6 & 3.00 \\
\hline
\end{tabular}

Sumber : Data hasil penelitian tahun 2021 berdasarkan Peraturan Menteri dan UKM RI No:

06/Per/Dep.6/IV/2016

Berdasarkan hasil analisis yang telah dilakukan menunjukan bahwa rasio modal sendiri terhadap total aset pada Koperasi Karyawan Bank Mandiri tahun 2017 sampai 2019 memperoleh hasil rata-rata sebesar $70.19 \%$. dan skor rata-rata memperoleh 3.00 .

\section{Rasio Modal Sendiri Terhadap Pinjaman Diberikan Yang Berisiko}

Rasio modal sendiri terhadap pinjaman diberikan yang berisiko merupakan perbandingan anatra modal sendiri terhadap pinjaman berisiko yang dimiliki oleh Koperasi Karyawan Bank Mandiri Wilayah II Palembang pada tahun yang bersangkutan. Berikut ini hasil analisis Rasio Modal Sendiri Terhadap Pinjaman Diberikan Yang Berisiko pada koperasi karyawan bank mandiri wilayah II Palembang:

Rasio Modal Sendiri Terhadap Pinjaman Diberikan Yang Berisiko

$$
=\frac{\text { Modal sendiri }}{\text { Pinjaman diberikan yang beresiko }} \times 100 \%
$$


Tahun $2017=\frac{\operatorname{Rp~} 1.934 .878 .901,02}{\operatorname{Rp} 1.675 .219 .134,00} \times 100 \%$

$$
=1.15500=115.50 \%
$$

Tahun $2018=\frac{\operatorname{Rp} 1.611 .745 .103,87}{\operatorname{Rp~} 1.419 .440 .440,39} \times 100 \%$

$$
=1.13547=113.54 \%
$$

Tahun $2019=\frac{\operatorname{Rp} 849.076 .278,5}{\operatorname{Rp} 854.549 .540,2} \times 100 \%$

$$
=0.99359=99.35 \%
$$

Berdasarkan perhitungan rasio modal sendiri terhadap pinjaman diberikan yang berisiko, selanjutnya dapat dilakukan penskoran pada hasil tersebut. Penskoran untuk rasio modal sendiri terhadap pinjaman diberikan yang berisiko disajikan dalam tabel berikut ini.

Table 3. Penskoran Rasio Modal Sendiri Terhadap Pinjaman Diberikan Yang Berisiko

\begin{tabular}{ccccc}
\hline Tahun & Rasio Modal (\%) & Nilai & Bobot (\%) & Skor \\
\hline 2017 & $115.50 \%$ & 100 & 6 & 6.00 \\
2018 & $113.54 \%$ & 100 & 6 & 6.00 \\
2019 & $99.35 \%$ & 100 & 6 & 6.00 \\
Rata-Rata & $109.46 \%$ & 100 & 6 & 6.00 \\
\hline
\end{tabular}

Sumber: Data hasil penelitian tahun 2021 berdasarkan Peraturan Menteri dan UKM RI No:

06/Per/Dep.6/IV/2016

Berdasarkan hasil analisis yang telah dilakukan menunjukan bahwa rasio modal sendiri terhadap pinjaman diberikan yang berisiko pada Koperasi Karyawan Bank Mandiri tahun 2017 sampai 2019 memperoleh hasil rata-rata sebesar 109.46\%. dan skor rata-rata memperoleh skor 6.00 .

\section{Rasio Kecukupan Modal Sendiri}

Rasio kecukupan modal sendiri merupakan perbandingan antara modal sendiri tertimbang terhadap aktiva tertimbang menurut resiko (ATMR). Berikut ini hasil analisis rasio kecukupan modal sendiri pada koperasi karyawan bank mandiri wilayah II Palembang :

Rasio Kecukupan Modal Sendiri

$$
=\frac{\text { Modal Tertimbang }}{\text { ATMR }} \times 100 \%
$$

Tahun $2017=\frac{\operatorname{Rp} 241.242 .362 .620,34}{\operatorname{Rp~1.626.828.725.901~}} \times 100 \%$

$$
=0.14828=14.83 \%
$$

Tahun $2018=\frac{\operatorname{Rp} 197.315 .679 .725,12}{\operatorname{Rp} 1.444 .458 .932 .912} \times 100 \%$

$$
=0.13660=13.66 \%
$$

Tahun $2019=\frac{\operatorname{Rp} 77.780 .027 .780,04}{\operatorname{Rp~868.642.959.292}} \times 100 \%$

$$
=0.08954=8.95 \%
$$

Berdasarkan perhitungan rasio kecukupan modal sendiri selanjutnya dapat dilakukan penskoran pada hasil tersebut. Penskoran untuk rasio kecukupan modal sendiri disajikan dalam tabel berikut ini.

Table 4. Penskoran Rasio Kecukupan Modal Sendiri

\begin{tabular}{ccccc}
\hline Tahun & Rasio Modal (\%) & Nilai & Bobot (\%) & Skor \\
\hline 2017 & $14.83 \%$ & 100 & 3 & 3.00 \\
2018 & $16.15 \%$ & 100 & 3 & 3.00 \\
2019 & $8.95 \%$ & 100 & 3 & 3.00 \\
\hline
\end{tabular}




$\begin{array}{lllll}\text { Rata-rata } & 13.31 \% & 100 & 3 & 3.00\end{array}$

Sumber : Data hasil penelitian tahun 2021 berdasarkan Peraturan Menteri dan UKM RI No :

06/Per/Dep.6/IV/2016

Berdasarkan hasil analisis yang telah dilakukan menunjukan bahwa rasio kecukupan modal sendiri pada Koperasi Karyawan Bank Mandiri tahun 2017 sampai 2019 memperoleh hasil ratarata sebesar 13.31\%. dan pada tahun 2017 rasio yang diperoleh sebesar $14.83 \%$ sehingga mendaptkan nilai sebesar 100 dengan skor 3.00.

Tabel 5. Penskoran Akhir Koperasi Karyawan Bank Mandiri Wilayah II Palembang tahun 20172019

\begin{tabular}{lccc}
\hline \multicolumn{1}{c}{ Aspek permodalan } & Skor 2017 & Skor 2018 & Skor 2019 \\
\hline Rasio Modal Sendiri Terhadap Total Aset & 3.00 & 3.00 & 3.00 \\
Rasio Modal Sendiri Terhadap Pinjaman & 6.00 & 6.00 & 6.00 \\
Diberikan Yang Berisiko & & & \\
Rasio Kecukupan Modal Sendiri & 3.00 & 3.00 & 3.00 \\
Total Skor Aspek Permodalan & 12 & 12 & 12 \\
\hline
\end{tabular}

Tabel 6. Perhitungan Predikat Penilaian Aspek Permodalan

\begin{tabular}{cccc}
\hline & & \multicolumn{2}{c}{ Total Keseluruhan Skor Permodalan 15 } \\
Skor & Predikat & Total Keselurah Skor Aspek 100 \\
Skor & Predikat \\
\hline $80.00 \leq \mathrm{x} \leq 100$ & Sehat & $12 \leq \mathrm{x} \leq 15$ & Sehat \\
$66.00 \leq \mathrm{x}<80.00$ & Cukup Sehat & $9.9 \leq \mathrm{x}<12$ & Cukup sehat \\
$51.00 \leq \mathrm{x}<66.00$ & Dalam pengawasan & $7.65 \leq \mathrm{x}<9.9$ & Dalam pengawasan \\
$<51.00$ & Dalam pengawasan khusus & $<7,65$ & Dalam pengawasan khusus \\
$\begin{array}{c}\text { Perhitungan: } \\
\frac{80}{100} x 15=12\end{array}$ & & \\
$\frac{66}{100} x 15=9.9$ & & & \\
$\frac{51}{100} x 15=7.65$ & & & \\
\hline
\end{tabular}

Sumber: Data Diolah Peneliti Dari peraturan menteri No. 06/Per/Dep.6/IV/2016

\section{Rasio Modal Sendiri Terhadap Total Aset}

Pada Tahun 2017 sampai dengan tahun 2019 rasio modal sendiri terhadap total aset yang terjadi berturut-turut pada tahun 2017 sebesar 65.26\%, kemudian meningkat pada tahun 2018 sebesar $71.84 \%$ dan pada tahun 2019 sebesar 73.48\% sehingga perhitungan mendapatkan nilai 50 dan mendapatkan skor 3.00 artinya sesuai dengan standar pengukuran cukup sehat sebagaimana tercantum dalam peraturan kementerian koperasi dan usaha kecil menengah No: 06/Per/Dep.6/IV/2016. Hal ini berarti Koperasi Karyawan Bank Mandiri Wilayah II Palembang mempunyai aspek permodalan yang cukup untuk menjamin seluruh total asetnya apabila suatu waktu koperasi mengalami pailit dan harus dilikuidasi sehingga koperasi tersebut dapat diharapkan menyimbangi antara modal sendiri dengan modal pinjaman. Dengan salah satu cara yaitu menarik anggota mau menabung dikoperasi atau mengumpulkan dana cadangan (Turi, 2014).

\section{Rasio Modal Sendiri Terhadap Pinjaman Diberikan Yang Berisiko}

Pada Tahun 2017 sampai dengan tahun 2019 rasio modal sendiri terhadap pinjaman diberikan yang berisiko yang terjadi berturut-turut sebesar $115.50 \%, 113.54 \%$, dan $99.35 \%$ sehingga mendapatkan nilai 100 dan mendapatkan skor 6.00 artinya modal sendiri koperasi memiliki kualitas cukup baik dalam menjamin pinjaman yang seluruh total pinjaman yang berisiko 
dimiliki koperasi apabila suatu waktu pinjaman yang diberikan oleh koperasi tidak dapat dibayarkan oleh para peminjam koperasi sebagimana tercantum dalam peraturan kementerian koperasi dan usaha kecil menengah No: 06/Per/Dep.6/IV/2016. sehingga koperasi tersebut dapat diharapakan meningkatkan jumlah modal sendiri di tahun-tahun berikut nya dan dapat meminimalisirkan jumlah pinjaman yang berisiko.

\section{Rasio Kecukupan Modal Sendiri}

Pada Tahun 2017 sampai dengan tahun 2019 Rasio Kecukupan Modal Sendiri yang terjadi berturut-turut sebesar 14.83\%, 16.15\% dan $8.95 \%$ sehingga mendapatkan nilai 100 dan mendapatkan skor 3.00 artinya modal tertimbang Koperasi Karyawan Bank Mandiri memiliki kualitas baik sebagimana tercantum dalam peraturan kementerian koperasi dan usaha kecil menengah No : 06/Per/Dep.6/IV/2016. Dalam mendukung adanya Aktiva Tertimbang Menurut Resiko (ATMR) apabila suatu waktu aset koperasi harus dilikuidasi sehingga koperasi tersebut dapat diharapakan meningkatkan dan mempertahankan kualitas modal tertimbang yang dimiliki.

Jadi untuk aspek permodalan tahun 2017 penilaian skor akhirnya 12. Skor akhirnya untuk aspek permodalan tahun 2018 sebesar 12, sedangkan tahun 2019 skor akhirnya untuk aspek permodalan sebesar 12. Hal ini menunjukkan bahwa aspek permodalan Koperasi Karyawan Bank Mandiri Wilayah II Palembang mengalami stabil dari tahun ke tahun. Dalam pedoman penilaian aspek permodalan total skor yang dapat dicapai yakni 12 artinya dalam Koperasi Karyawan Bank Mandiri Wilayah II Palembang memiliki aspek permodalan yang sehat, oleh karena itu Koperasi Karyawan Bank Mandiri Wilayah II Palembang perlu mempertahankan dan meningkatkan lagi jumlah modal sendiri di tahun-tahun berikutnya. Permodalan merupakan dana yang akan digunakan untuk melaksanakan usaha-usaha koperasi (Diana, 2018).

\section{SIMPULAN}

Berdasarkan hasil penelitian dan pembahasan pada aspek permodalan Koperasi Karyawan Bank Mandiri Wilayah II Palembang berdasarkan Peraturan Kementerian Koperasi Dan Usaha Kecil Menengah Republik Indonesia No: 06/Per/Dep.6/IV/2016 Berdasarkan hasil rasio modal sendiri terhadap total aset pada Koperasi Karyawan Bank Mandiri Wilayah II Palembang dari tahun 2017 sampai dengan tahun 2019 adalah hasil rata-rata sebesar 70.19\%. sehingga rasio modal sendiri terhadap total aset mendapatkan memperoleh nilai 3.00. sebagai angka skor akhirnya artinya sesuai dengan standar pengukuran cukup sehat. Berdasarkan hasil rasio modal sendiri terhadap pinjaman diberikan yang berisiko pada Koperasi Karyawan Bank Mandiri Wilayah II Palembang dari tahun 2018 sampai dengan tahun 2019 adalah memperoleh hasil rata-rata sebesar 109.46\%. dan mendapatkan memperoleh nilai 6.00 sebagai skor akhirnya artinya modal sendiri koperasi memiliki kualitas cukup baik. Berdasarkan hasil rasio kecukupan modal sendiri pada Koperasi Karyawan Bank Mandiri Wilayah II Palembang dari tahun 2018 sampai dengan tahun 2019 adalah memperoleh hasil rata-rata sebesar 13.31\% dan mendapatkan memperoleh nilai 3.00. sebagai angka skor akhirnya artinya modal tertimbang Koperasi Karyawan Bank Mandiri memiliki kualitas baik. Berdasarkan hasil analisis terhadap laporan keuangan aspek permodalan pada Koperasi Karyawan Bank Mandiri Wilayah II Palembang dari tahun 2017 samapai dengan 2019, maka aspek permodalan pada Koperasi Karyawan Bank Mandiri Wilayah II Palembang berada dalam kategori sehat. Hal ini dikarenakan skor untuk aspek permodalan sebesar 12. Dalam pedoman penilaian aspek permodalan total skor yang dpat dicapai yakni 15 sebagaimana tercantum pada Peraturan Menteri Koperasi Dan Usaha Kecil Menengah No. 06/Per/Dep.6/IV/2016.

\section{DAFTAR PUSTAKA}

Arikunto, S. (2013). Prosedur Penelitian Suatu Pendekatan Praktik. Jakarta: PT Rineka Cipta. Moleong, L. J. (2017). Metodologi Penelitian Kualitatif. Bandung: PT Remaja Rosdakarya. Subandi, D. (2015). Ekonomi Koperasi. Bandung: Alfabeta. Baswir, R. (2013). Koperasi Indoensia. Yogyakarta: BPFE-Yogyakarta Rudianto. (2010). Akuntansi Koperasi. Jakarta: Erlangga Turi. (2014). Akuntansi Koperasi Suatu Tinjauan Konsep dan Aplikasinya, Kendari: Unhalu Press. 
Sugiyono. (2019). Metode Penelitian Pendidikan (Kuantitatif, Kualitatif, Kombinasi, R\&D dan Penelitian Pendidikan). Bandung : Alfabeta.

Diana, S. R. (2018). Analisis Laporan Keuangan dan aplikasinya. Bojongkulur-Gunung Putri-Bogor: In Media.

Kurniawan, C., \& Arianti, V. D. (Juni 2018). Analisis Kinerja Keuangan Pada Koperasi Simpan Pinjam. Jurnal Neraca, Vol 2 No.1, 1-15.

Sudiyanto, (Maret 2019). Analisis Aspek Permodalan Pada Koperasi Multi Kharisma. Jurnal Mediasi, Vol 1 No 2, Maret 2019: 163-184.

Sakdia, (Desember 2019). Analisis Rasio Keuangan Untuk Menilai Kinerja Keuangan Pada Koperasi Pegawai Republik Indonesia (KPRI) Bakti Guru Palembang, Jurnal Neraca, Vol 3 No 2, Desember 2019: 168-184.

Peraturan Deputi Bidang Pengawasan Kementerian Koperasi dan Usaha Kecil dan Menegah Republik Indonesia Nomor : 06/Per/Dep.6/IV/2016 tentang Pedoman Penilaian Kesehtan Koperasi Simpan Pinjam dan Unit Simpan Pinjam Koperasi.

Undang-undang No. 25 tahun 1992 tentang perkoperasian

Undang-undang No. 12 tahun 1967 tentang perkoperasian 